\title{
Continuidades e transformações da teoria da ação de Max Weber entre 1913 e $1921^{1}$
}

\author{
Bruna dos Santos Bolda ${ }^{2}$
}

\section{RESUMO}

O ensaio Sobre algumas categorias da Sociologia Compreensiva foi publicado em 1913 e, após inúmeras críticas acerca da incompreensibilidade desse texto, Weber revisou-o e (re)publicou-o em 1921, com o título Conceitos Sociológicos Fundamentais. Em vista disso, neste artigo objetivamos discutir as alterações conceituais e tipológicas da teoria da ação de Weber realizadas de Categorias para Conceitos. Em 1913, ainda que Weber reflita sobre ações motivadas por fins, valores e afetos, ele não as considera como ações comunitárias. Quiçá trata as ações orientadas pela tradição e/ou pelo hábito como comportamentos. Por outro lado, em 1921, Weber admite a análise intelectual, tanto de ações racionais quanto de ações afetivas e tradicionais, o que equivale metodologicamente a dois tipos de ação racional: a de fins e a de valores. É importante ressaltar que em ambos os ensaios Weber prioriza a análise da ação racional, pois ela possui compreensibilidade evidente. Somente para fins de conveniência metodológica, a Sociologia Compreensiva é "racionalista". Com base nisso, defendemos que a possível normatividade racionalista, existente em Categorias, é nos Conceitos erradicada. Com o abandono da racionalidade objetivamente correta e a consequente adoção da racionalidade de fins e de valores, seu "racionalismo heurístico" perdeu a centralidade.

Palavras-chave: Max Weber; Teoria da Ação; Racionalismo Heurístico.

\begin{abstract}
The essay Sobre algumas categorias da sociologia compreensiva was published in 1913. After several critiques over the incomprehensibility of the text, Weber revised it and republished it in 1921 with the title Conceitos Sociológicos Fundamentais. With that in mind, we'll discuss the conceptual and typological changes in Max Weber's action theory from one to the other. In the 1913 version, even though Weber writes about actions oriented by ends, values, and affections, he does not consider them communitarian actions. On the other hand, in the 1921 version he allows for the intellectual analysis of rational as well as affectionate and traditional actions. Still, the rational action types are methodologically equivalent: goal rational action and value rational action. Weber gives priority to rational actions in both versions, given that they are immediately comprehensible. Weber's comprehensive sociology is only "rational" as a methodological convenience. With that in mind, we argue that the rationalist normativity, present in the Categorias, is eliminated in the Conceitos. As he abandons objectively correct rationality and adopts "means-ends" and "value' rationality", his "heuristic rationalism" loses centrality.
\end{abstract}

Keywords: Max Weber; Action Theory; Heuristic Rationalism.

\footnotetext{
${ }^{1}$ Uma primeira versão do texto foi apresentada na X edição do Seminário Nacional Sociologia \& Política da UFPR.

${ }^{2}$ A autora Bruna dos Santos Bolda é Mestranda em Sociologia Política na Universidade Federal de Santa Catarina (UFSC) e bolsista do Conselho Conselho Nacional de Desenvolvimento Científico e Tecnológico (CNPq). E-mail: bruna.bolda@hotmail.com.
} 


\section{Introdução}

Em setembro de 1914 estava agendado um debate sobre os juízos de valor nas Ciências Econômicas e Sociais na Associação de Política Social. Weber queria demarcar a sua posição sobre o assunto antes do evento, e, por isso, enviou o ensaio Sobre algumas categorias da Sociologia Compreensiva [Über einige Kategorien der verstehenden Soziologie] ${ }^{3}$ para a Revista Logos, em 1913. Por mais que os Elementos de Economia Social [Grundriss der Sozialökonomik] estivessem em processo de edição, com previsão próxima de publicação (prevista para 1914) e Weber tivesse que escrever sobre as Ciências Econômicas e Sociais, ele optou por publicar Kategorien em outro veículo.

Ocorreu que o texto publicado às pressas, em 1913, não teve a recepção positiva esperada pelo autor. Seu colega, Hermann Kantorowicz, por exemplo, criticou, por meio de correspondência, a incompreensibilidade do texto. Em vista disso, em 1917, em conversa com o editor Paul Siebeck, Weber manifestou a intenção de produzir uma publicação conjunta dos seus textos sobre metodologia. Tal publicação contaria com uma nova e mais acessível versão do texto de 1913 (SCHLUCHTER, 2014).

Apesar da compilação de seus textos metodológicos não ter sido publicada em vida, a nova e mais acessível versão do texto de 1913 foi divulgada postumamente em Economia e Sociedade [Wirtschaft und Gesellschaft] ${ }^{4}$, com o título Conceitos Sociológicos Fundamentais [Soziologische Grundbegriffe]5. Na nota preliminar de Grundbegriffe, Weber esclarece que esse não é um assunto inédito em sua obra e que sua intenção com o ensaio era, antes, formular de maneira mais clara e correta o que já havia sido discutido em 1913. Quando oportuno e necessário, a sua terminologia foi simplificada e modificada.

No debate sobre a as mudanças e/ou permanências conceituais do texto de 1913 e de 1921, há duas posições contrárias. Schluchter (2014, p. 195), em consonância com o argumento de Weber na nota preliminar do texto de 1921, defende que entre os dois textos há somente um refinamento do aparato léxico, e, portanto, não há "duas

\footnotetext{
3 Doravante, Kategorien (1913).

4 Doravante, $W u G$.

5 Doravante, Grundbegriffe (1921).
} 
Sociologias" distintas entre si: "de fato, 'Conceitos sociológicos fundamentais' apresenta, em relação ao escrito 'Categorias', uma terminologia mais compreensível e simplificada”.

Schluchter (2014) assegura que Grundbegriffe (1921) substitui Kategorien (1913), do ponto de vista da história da obra, afinal, ambos os textos desempenham o mesmo papel de introduzir o leitor de $W u G$ aos métodos e conceitos da Sociologia Compreensiva. A diferença entre esses textos é que o de 1921 foi desenvolvido para introduzir um conjunto de textos de mesmo aparato conceitual (os textos escritos para $W u G$ no período pós-Guerra). Já o texto de 1913, sob a perspectiva de Schluchter (2014), apesar de inicialmente ser escrito como introdução à parte antiga da $W u G$, não está situado em um conjunto de textos coerentes e de mesmo aparato conceitual. Isso porque os textos escritos antes da primeira Guerra são de diferentes fases e características.

Klaus Lichtblau (2015), por outro lado, argumenta que os dois textos em questão possuem diferentes abordagens sociológicas. Ao longo de sua trajetória intelectual, o interesse de Weber foi gradualmente se deslocando de uma ciência individualizante (histórica) ${ }^{6}$ para uma ciência generalizante (sociológica). À vista disso, Lichtblau afirma que a Sociologia pré-guerra de Weber - como o texto Kategorien (1913) - é orientada por uma teoria dos estágios de desenvolvimento, ainda em proximidade com a história do desenvolvimento.

Já no texto de 1921, Weber evidentemente distancia a Sociologia e a História. O autor caracteriza a Sociologia como a ciência que atenta para as generalidades dos fenômenos sociais e para os significados das orientações das ações. Com base nisso, Lichtblau (2015) afirma que a Sociologia Compreensiva de Weber não é a mesma em 1913 e em 1921. Weber formulou, ao longo de seus escritos, duas Sociologias distintas: uma de característica individualizante, em conexão com a história, e outra efetivamente sociológica.

Em vista desse embate, objetivamos discutir as alterações conceituais, tipológicas e de conteúdo da teoria da ação de Weber, por meio de uma análise

${ }^{6}$ Comumente, em seus textos do início da década de 1910, Weber trata as "ciências culturais" em proximidade com a definição de Rickert, como a economia e a história (LICHTBLAU, 2015). 
comparada de Kategorien e de Grundbegriffe. A pergunta que norteia este estudo é: Weber possui duas teorias da ação distintas? Para responder a essa inquietação, inicialmente discutiremos as aproximações e distanciamentos entre a definição de ação significativa para a análise sociológica de 1913 e de 1921, e, logo após, tomando a estrutura conceitual de Grundbegriffe como parâmetro, compararemos a formulação final dos tipos de ação àquela embrionariamente desenvolvida em Kategorien.

\section{A ação em contexto social}

Imaginemos dois ciclistas andando em sentidos opostos da mesma rodovia, um conduzindo sua bicicleta em direção norte e o outro em direção sul. Em um dado momento, ambos os condutores desviam a atenção e colidem. Tal colisão é uma simples ação humana. Imaginemos agora que logo após a colisão os condutores tentam realizar uma negociação amistosa dos danos físicos causados as suas bicicletas. Há, nessa situação, uma ação em contexto social, já que está orientada subjetivamente pela expectativa objetiva da ação do outro ator. Ambas as dimensões elucidam as propriedades racionais dos agentes, afinal, os atores sustentam subjetivamente a sua expectativa7 $^{7}$ ao levarem em consideração a média das demais ações racionais de sentido subjetivo.

Em vista disso, uma ação no contexto social somente é significativa para a Sociologia quando é uma conduta em que: 1) o significado subjetivamente visado pelo agente se relaciona com a conduta de outros agentes; 2) o decurso é coorientado por si mesmo e pelas ações dos outros; e 3) pode ser explicada compreensivelmente ${ }^{8}$ por seu

7 Em Estudos críticos sobre a lógica das ciências da cultura (1906), Weber trata a possibilidade objetiva e a expectativa como coisas inteiramente opostas. A possibilidade objetiva seria algo objetivo a ser conhecido, já a expectativa seria uma possessão inteiramente subjetiva. Em Rudolf Stammler e a "superação" da concepção materialista da história (1907), a expectativa aparece como um fato empírico, uma causa. Todavia, foi somente em Kategorien que Weber (1913) explorou e refinou a distinção entre possibilidade objetiva e possibilidade subjetiva (ou expectativa). Aqui, as possibilidades objetivas são elas mesmas as causas das expectativas (TURNER, 1983).

${ }^{8}$ As Ciências Sociais, ao não formularem leis gerais dos fenômenos sociais, conseguem integrar tanto o princípio compreensivo do sentido das ações quanto o princípio explicativo das causas e motivações. Conforme a defesa de Schluchter (2014), Weber nos leva a uma terceira posição no debate epistemológico: a Sociologia Compreensivo-Explicativa. Ele integra tanto o princípio causalista típico nas Ciências Naturais quanto o princípio hermenêutico das Ciências Sociais. Assim, Weber considera 
sentido subjetivamente visado. Tal objeto primário da Sociologia está retratado de formas distintas em Kategorien e em Grundbegriffe, conforme ilustra o Quadro 1.

Quadro 1 - Definição de ação significativa em 1913 e 1921

\begin{tabular}{|c|c|}
\hline \multirow{3}{*}{$\begin{array}{c}1913 \\
\text { (parte } \\
\text { 'antiga') }\end{array}$} & $\begin{array}{l}\text { TRECHO ORIGINAL } \\
\text { “Von 'Gemeinschaftshandeln’ wollen wir da sprechen, wo menschliches Handeln } \\
\text { subjektiv sinnhaft auf das Verhalten anderer Menschen bezogen wird. [...] Einen } \\
\text { wichtigen normalen - wenn auch nicht unentbehrlichen - Bestandteil des } \\
\text { Gemeinschaftshandelns bildet insbesondere dessen sinnhafte Orientierung an den } \\
\text { Erwartungen eines bestimmten Verhaltens Anderer und den darnach für den Erfolg des } \\
\text { eigenen Handelns (subjektiv) geschätzten Chancen” (MWG 1/12, p. 406). }\end{array}$ \\
\hline & TRECHO TRADUZIDO \\
\hline & $\begin{array}{l}\text { “Nós falamos em 'ação em comunidade', em que a ação humana refere-se subjetiva e } \\
\text { significantemente ao comportamento de outras pessoas. [...] Um componente normal } \\
\text { importante - embora não indispensável - da ação em comunidade é a sua orientação } \\
\text { particularmente significativa norteada por expectativas de um comportamento } \\
\text { específico de outros e orientado pelas chances subjetivamente estimadas do sucesso das } \\
\text { próprias ações." (tradução nossa). (tradução nossa). }\end{array}$ \\
\hline \multirow{4}{*}{1921} & TRECHO ORIGINAL \\
\hline & $\begin{array}{c}\text { Parágrafo 1: "Soziales' Handeln aber soll ein solches Handeln heißen, welches seinem } \\
\text { von dem oder den Handelnden gemeinten Sinn nach auf das Verhalten anderer } \\
\text { bezogen wird und daran in seinem Ablauf orientiert ist" (MWG 1/23) } \\
\text { Nota ı da Parte 2: "Soziales Handeln (einschließlich des Unterlassens oder Duldens) } \\
\text { kann orientiert werden am vergangenen, gegenwärtigen oder für künftig erwarteten } \\
\text { Verhalten anderer (Rache für frühere Angriffe, Abwehr gegenwärtigen Angriffs, } \\
\text { Verteidigungsmaßregeln gegen künftige Angriffe)" (MWG 1/23,) }\end{array}$ \\
\hline & TRECHO TRADUZIDO \\
\hline & $\begin{array}{c}\text { Parágrafo 1: “Ação ‘social', por sua vez, significa uma ação que, quanto a seu sentido } \\
\text { visado pelo agente ou os agentes, refere se ao comportamento de outros, } \\
\text { orientando-se por este em seu curso." (WEBER, 1921, p. 3). } \\
\text { Nota 1 da Parte 2: “A ação social (incluindo omissão ou tolerância) orienta-se pelo } \\
\text { comportamento de outros, seja este passado, presente ou esperado como futuro } \\
\text { (vingança por ataques anteriores, defesa contra ataques presentes ou medidas de defesa } \\
\text { para enfrentar ataques futuros).” (WEBER, 1921, p. 13). }\end{array}$ \\
\hline
\end{tabular}

Fonte: elaborado pela autora (2019).

Weber (1921) desenvolveu, em Grundbegriffe, a ação social [soziales Handeln] como o objeto primário para a Sociologia Compreensiva, e as características que a diferem da simples 'ação' são: 1) referência subjetiva (seu sentido refere-se ao comportamento de outros - seja esse um comportamento encerrado, decorrido, em curso, em processo, intencionado ou esperado no futuro); e 2) referência objetiva (a orientação externa do curso da ação também refere-se ao comportamento alheio).

possível explicar as ações humanas em suas regularidades causais e compreender seus conteúdos de sentido. 
O objeto primário da Sociologia Compreensiva é, em Kategorien, outro: a ação em comunidade [Gemeinschaftshandeln]. São duas as suas características fundamentais que a diferem da 'ação': 1) referência subjetiva (é uma ação que possui seu sentido orientado segundo as expectativas de comportamento alheio); e 2) está assentada na probabilidade calculada de êxito (a possibilidade objetiva [objective Möglichkeit] ${ }^{9}$, para utilizar o léxico weberiano). Em seu caso limite racional, podemos defini-la como uma ação humana que tem seu conteúdo de sentido orientado subjetivamente pela expectativa do comportamento objetivo de outro ator ou de outros atores.

Em 1921, a referência ao comportamento alheio é dupla. Weber concebe a orientação tanto do sentido quanto do curso da ação pessoal pelo comportamento de outrem. Já em 1913 ele contempla a referência direta ao comportamento alheio no nível do sentido subjetivo, mas em seu curso externo a ação assenta-se no cálculo do sucesso e êxito próprio. Isso significa que o agente considera as ações alheias no desenvolvimento de sua própria ação, especialmente como um material de fins. Todavia, os atores não orientam o curso de suas ações diretamente pela expectativa do comportamento alheio. Segundo Wolfgang Ludwig Schneider (2014), o significado subjetivamente pretendido cumpre, aqui, a orientação do agir.

Em outras palavras, a ação social refere-se ao comportamento alheio, tanto em dimensão subjetiva (sentido) quanto em dimensão objetiva (curso da ação), ao passo em que a ação em comunidade refere-se ao comportamento de outrem, especificamente no âmbito subjetivo (sentido). A dimensão objetiva da ação em comunidade fica reservada à probabilidade maior ou menor de que as expectativas da ação dos demais se sustentem na prática. Em ambos os textos, de todo modo, Weber

\footnotetext{
9 John Stuart Mill, o inaugurador da tese da possibilidade objetiva, a compreendia como o equilíbrio entre os fatores que favorecem determinado desfecho de um fenômeno e os fatores que evitam tal desfecho. Mas é com a teoria da adequação causal, de Von Kries, que Weber dialoga, especificamente em Estudos críticos sobre a lógica das ciências da cultura [Kritische Studien auf dem Gebiet der kulturwissenschaftlichen Logik]. Von Kries transportou o método causalista das Ciências Naturais para as Ciências Sociais, pois defendia que havia conhecimento nomológico também na possibilidade objetiva das conexões causais na análise causal na jurídica: a adequação causal. Na prática, de acordo com Weber (1906), o pesquisador deve procurar compreender o motivo (intenção) da ação dos atores, e, então, verificar se esse motivo efetivamente levou às consequências (efeito) em questão. É necessário pensar contrafactualmente, imaginar como se desenvolveria um determinado acontecimento se sua causa fosse outra ou ausente e quais seriam as divergências possíveis em cursos de ações esperados. Isso é possível graças a nosso conhecimento probabilístico e a nossa capacidade de fabricar possibilidades objetivas e factíveis para os fenômenos.
} 
(1913, 1921) entende a ação em contexto social concomitantemente como algo intimamente individual (por possuir sentido subjetivo) que está em relação ao geral (por referir-se ao comportamento alheio).

O grau máximo de evidência e compreensão é adquirido na análise de uma ação racional com referência a fins, pois atores e sociólogos compartilham, aqui, o mesmo padrão de racionalidade. Desse modo, Weber inter-relaciona três componentes de uso heurístico típicos da ação em comunidade de Kategorien: razões, causas e expectativas. Quando assumimos a racionalidade objetivamente correta em uma análise sociológica, ainda que despropositadamente, aceitamos que as probabilidades atuais de decorrência de uma ação coincidem com sua efetivação prática. Isso indica a probabilidade de que uma ação se concretize segundo as regras da experiência, segundo as expectativas comprovadas por ações anteriores típicas (SCHÜTZ, 2018).

Conforme defesa de Wolfgang Schluchter (2014, 2011) e de Jens Greve (2014), em Weber haveria um racionalismo heurístico que priorizaria a análise, a descoberta e a investigação dos fatos por meio da ação racional. Weber nos passa a impressão, em Kategorien, de que a racionalidade de fins seria a única forma plenamente racional de ação. Somente ela estaria efetivamente passível de adequação de sentido, de se desenrolar empiricamente de forma mais ou menos próxima da formulação intelectual (SCHLUCHTER, 2014).

Assim como em Kategorien, em Grundbegriffe Weber prioriza a análise da ação racional com referência a fins, pois ela possui compreensibilidade evidente. Essa é a ação que se orienta pela expectativa do comportamento dos outros agentes, e que, com base nisso, organiza estrategicamente seus meios, a fim de alcançar o grau máximo de probabilidade de êxito. Ela também serve como um tipo ideal que permite compreender, por meio de comparação com um comportamento puramente racional, os 'desvios' influenciados por irracionalidades de diversos tipos em ações reais.

Somente para fins de conveniência metodológica, a Sociologia Compreensiva é 'racionalista'. O sociólogo não pode, portanto, acreditar que na vida cotidiana há a predominância de ações racionais. Segundo Karl-Siegbert Rehberg (2014), embora Weber não acreditasse que a maioria das ações observáveis fossem motivadas 
'racionalmente', ou mesmo "propositalmente racional", ele preferia servir "ao racional da finalidade como um tipo ideal".

A diferença do texto de 1921, quando comparado ao de 1913, é que Weber admite a análise intelectual, tanto de ações racionais quanto de ações irracionais (como as ações intuitivas ou impulsos afetivos). Ainda que essas ações tenham menor grau de evidência, elas são suficientes para a explicação sociológica. A possível interpretação de uma normatividade racionalista, existente em Kategorien, é em Grundbegriffe esvairida.

Em 1921 Weber abandona a "racionalidade objetivamente correta" e adota, além da racionalidade de fins, a racionalidade valorativa. Sob essa perspectiva, afirma Schluchter (2014), o agente adota a racionalidade subjetiva final ou a racionalidade subjetiva valorativa. A ação orientada por valores, adverte Schluchter (2014), é uma ação que tem seu conteúdo de significado relacionado com a ação de outros agentes e está organizada em função da crença subjetiva em um determinado valor (como, por exemplo, o dever).

\section{Os tipos de ação}

Feitas as notas introdutórias acerca do conceito de ação de Weber, é possível, então, adentrar na discussão dos tipos de ação de Kategorien e de Grundbegriffe. Para tanto, o esquema tipológico da ação social desenvolvido em 1921 é assumido como referência e utilizado como parâmetro de comparação com o esquema 'embrionário' de 1913. Emprega-se o termo 'embrionário', pois em Kategorien Weber não tinha uma clara tipologia da ação que abrangesse a ação tradicional, ação afetiva, ação racional com referência a valores e ação racional com referência a fins. No texto de 1913 ele desenvolveu apenas algumas reflexões 'diluídas' sobre ações motivadas por afetos, valores e fins, conforme o Quadro 2 sistematiza.

Quadro 2 - Tipos de ação de Kategorien e de Grundbegriffe 


\begin{tabular}{|c|c|}
\hline & 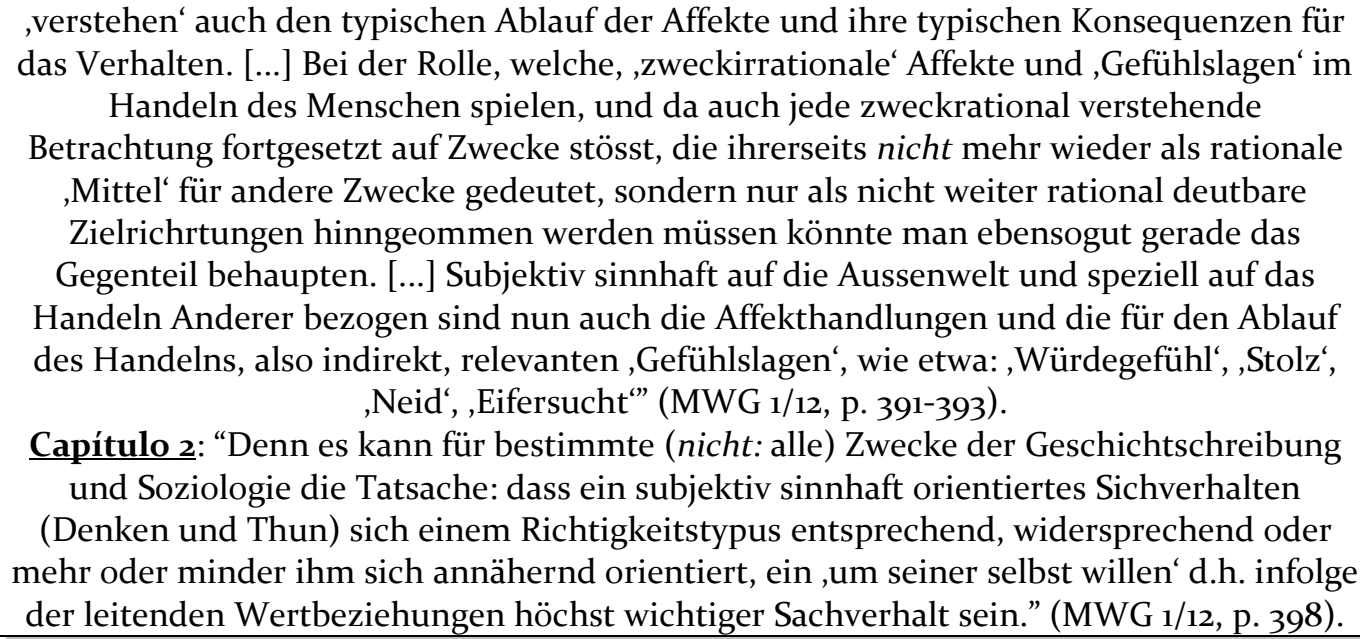 \\
\hline & $\begin{array}{l}\text { TRECHO TRADUZIDO } \\
\text { Capítulo 1: “Por comportamento racional com referência a fins entende-se aquele } \\
\text { orientado exclusivamente por meios subjetivamente avaliados como adequados para } \\
\text { alcançar fins (subjetivamente) claramente compreendidos. De modo algum } \\
\text { compreendemos somente a ação racional: nós compreendemos também o curso típico } \\
\text { dos afetos e suas consequências típicas para o comportamento. [...] Poderia-se se também } \\
\text { alegar o contrário, dado o papel que os fins irracionais como os afetos e os estados } \\
\text { emocionais desempenham na ação humana, e visto que cada contemplação que } \\
\text { compreende de forma racional orientado pelos fins, de forma contínua encontra fins que } \\
\text { eles mesmos da sua parte não podem mais ser interpretados novamente como ,meios‘ } \\
\text { racionais para outros fins, mas apenas precisam ser aceitos como orientações que não } \\
\text { podem mais ser racionalmente interpretados. [...] Subjetivamente significativos em } \\
\text { relação ao mundo exterior e especialmente às ações de outros, são também as ações } \\
\text { afetivas, e os ‘estados emocionais' indiretamente relevantes para o curso das ações, tais } \\
\text { como: 'dignidade', 'orgulho', 'inveja', 'ciúme.”" (tradução nossa) } \\
\text { Capítulo 2: "Pois o fato que um comportamento interno subjetivamente significativo } \\
\text { (pensar e fazer) corresponde a um tipo objetivamente correto, contraditório ou mais ou } \\
\text { menos aproximado pode ser uma situação (uma circunstância) de máxima importância } \\
\text { para certos (porém não para todos) fins da historiografia e da sociologia, "por si mesmo”, } \\
\text { quer dizer, devido às relações de valores condutivos.” (tradução nossa) }\end{array}$ \\
\hline \multirow[t]{2}{*}{$\begin{array}{c}1913 \\
\text { (parte } \\
\text { antiga) }\end{array}$} & $\begin{array}{l}\text { TRECHO ORIGINAL } \\
\text { Capítulo 4: “Der mögliche (subjektiv gemeinte) Sinn des Gemeinschaftshandelns } \\
\text { erschöpft sich freilich nicht etwa in der Orienterung speziell an ,Erwartungen` des } \\
\text {,Handelns` Dritter. Im Grenzfall kann davon gänzlich abgesehen und das auf Dritte } \\
\text { sinnbezogene Handeln lediglich an dem subjektiv geglaubten ,Wert` seines Sinngehalts } \\
\text { als solchen (,Pflicht‘ oder was es sei) orientert, das Handeln also nicht } \\
\text { erwartungsorientiert, sondern wertorientiert sein. Ebenso muss bei den ,Erwartungen‘ } \\
\text { nicht ein Handeln, sondern es kann auch z.B. nur ein inneres Sichverhalten (etwa eine } \\
\text {,Freude`) des Dritten den Inhalt der Erwartung ausmachen. Der Übergang vom } \\
\text { Idealtypus des sinnhaften Bezogenseins des eignen auf ein sinnhaftes Verhalten des } \\
\text { Dritten endlich zu dem Fall, wo der Dritte (etwa ein Säugling) lediglich als ,Objekt‘ in } \\
\text { Betracht kommt, ist empirisch durchaus flüssig.” (MWG 1/12, p. 407). }\end{array}$ \\
\hline & $\begin{array}{l}\text { TRECHO TRADUZIDO } \\
\text { Capítulo 4: “O sentido possível da ação comunitária (entendido em um sentido } \\
\text { subjetivo) não se esgota em sua orientação, pelas expectativas da ação de terceiros. No } \\
\text { caso limite, a ação relacionada a terceiros pode estar somente orientada por um 'valor' } \\
\text { subjetivo ('dever' ou o que quer que seja), ou seja, ação não é orientada pela expectativa, } \\
\text { mas pelo valor. Da mesma forma, o conteúdo das 'expectativas' não precisa } \\
\text { necessariamente se referir a uma ação, mas pode se referir também a um comportamento } \\
\text { interior (como a 'alegria') de um terceiro. Finalmente, no caso em que um terceiro (por }\end{array}$ \\
\hline
\end{tabular}




\begin{tabular}{|c|c|}
\hline & $\begin{array}{c}\text { exemplo um bebê) é considerado apenas um objeto, a transição do tipo ideal de } \\
\text { comportamento significativo pessoal a um comportamento significativo do terceiro é } \\
\text { empiricamente fluída." (tradução nossa). }\end{array}$ \\
\hline \multirow{4}{*}{1921} & TRECHO ORIGINAL \\
\hline & $\begin{array}{c}\text { Parágrafo } 2 \text { da parte 2: “Wie jedes Handeln kann auch das soziale Handeln bestimmt } \\
\text { sein 1) zweckrational: durch Erwartungen des Verhaltens von Gegenständen der } \\
\text { Außenwelt und von andren Menschen und unter Benutzung dieser Erwartungen als } \\
\text {,Bedingungen` oder als ,Mittel' für rational, als Erfolg, erstrebte und abgewogene eigne } \\
\text { Zwecke; 2) wertrational: durch bewußten Glauben an den - ethischen, ästhetischen, } \\
\text { religiösen oder wie immer sonst zu deutenden - unbedingten Eigenwert eines } \\
\text { bestimmten Sichverhaltens rein als solchen und unabhängig vom Erfolg; 3) affektuell, } \\
\text { insbesondere emotional: durch aktuelle Affekte und Gefühlslagen; 4) traditional: durch } \\
\text { eingelebte Gewohnheit.” (MWG 1/23). }\end{array}$ \\
\hline & TRECHO TRADUZIDO \\
\hline & $\begin{array}{l}\text { Parágrafo } 2 \text { da parte 2: “A ação social, como toda ação, pode ser determinada: 1) de } \\
\text { modo racional referente a fins: por expectativas quanto ao comportamento de objetos do } \\
\text { mundo exterior e de outras pessoas, utilizando essas expectativas como 'condições' ou } \\
\text { 'meios'; 2) de modo racional referente a valores: pela crença consciente no valor - ético, } \\
\text { estético, religioso ou qualquer que seja sua interpretação - absoluto e inerente a } \\
\text { determinado comportamento como tal, independentemente do resultado; 3) de modo } \\
\text { afetivo, especialmente emocional: por afetos ou estados emocionais atuais; 4) de modo } \\
\text { tradicional: por costume arraigado.” (WEBER, 1921, p. 15). }\end{array}$ \\
\hline
\end{tabular}

Fonte: elaborado pela autora (2019).

Na formulação final de sua Sociologia Compreensiva, Weber elenca quatro tipos ideais de ação social: a ação tradicional, a ação afetiva, a ação racional com referência a valores e a ação racional com referência a fins. Com isso, ele funda uma tipologia quadrialógica da ação, que abrange desde ações que estão no limite do comportamento reativo (como a ação tradicional), passando por ações motivadas por emoções pessoais (como a ação efetiva) e indo até ações efetivamente racionais (como a ação referente a valores e a referente a fins).

O Quadro 3 sistematiza o tratamento que Weber deu aos quatro tipos de ação social (tradicional, afetiva, racional com referência a valores e racional com referência a fins) na parte 'nova' e na parte 'antiga' de Kategorien e em Grundbegriffe. Com isso, é possível ter um panorama geral da tipologia weberiana das ações sociais.

Quadro 3 - Tipos de ação social de Kategorien e de Grundbegriffe

\begin{tabular}{|c|c|c|c|}
\hline Ações $\quad$ Textos & Parte 'nova' de 1913 & Parte 'antiga' de 1913 & 1921 \\
\hline Ação tradicional & Não há & Não há & $\begin{array}{c}\text { Ações sociais } \\
\text { automatizadas, } \\
\text { rotinizadas e quase } \\
\text { reativas }\end{array}$ \\
\hline Ação afetiva & Ações emocionais que & Comportamento interno & Ação social referida a \\
\hline
\end{tabular}




\begin{tabular}{|c|c|c|c|}
\hline & interferem indiretamente & $\begin{array}{c}\text { motivado por afetos e } \\
\text { emoções, mas não referido a } \\
\text { outro agente }\end{array}$ & afetos \\
\hline $\begin{array}{c}\text { Ação racional com } \\
\text { referência a } \\
\text { valores }\end{array}$ & $\begin{array}{c}\text { Comportamento interno } \\
\text { motivado por valores e } \\
\text { referido ao } \\
\text { comportamento de } \\
\text { outrem }\end{array}$ & $\begin{array}{l}\text { Comportamento interno } \\
\text { motivado por valores, mas não } \\
\text { referido ao comportamento de } \\
\text { outrem }\end{array}$ & $\begin{array}{l}\text { Ação social } \\
\text { racionalmente referida a } \\
\text { valores }\end{array}$ \\
\hline $\begin{array}{l}\text { Ação racional com } \\
\text { referência a fins }\end{array}$ & $\begin{array}{c}\text { Ação intimamente } \\
\text { instrumental e } \\
\text { objetivamente correta }\end{array}$ & $\begin{array}{c}\text { Ação orientada por fins e } \\
\text { referida ao comportamento } \\
\text { alheio }\end{array}$ & $\begin{array}{l}\frac{\text { Ação social }}{\text { racionalmente referida a }} \\
\text { fins }\end{array}$ \\
\hline
\end{tabular}

Fonte: elaborado pela autora (2019).

Em Grundbegriffe, a ação afetiva é determinada por estados emocionais e sentimentos. Dentre esses afetos, é possível destacar a satisfação das necessidades pessoais de vingança, de gozo, de entrega, de contemplação ou de descarga (brutal ou sublimada) de afetos. Assim, seu sentido da não está no resultado que a transcende, mas no próprio indivíduo e na satisfação de suas necessidades sentimentais e emocionais individuais.

Ainda que em Kategorien Weber tenha formalmente categorizado a ação societária e a ação por acordo como os sub-tipos de sua ação comunitária, ele desenvolveu algumas reflexões sobre a existência de ações influenciadas por afetos, valores e fins. Especificamente na parte 'nova' do texto de 1913, o autor brevemente discute a compreensibilidade do curso dos afetos e dos estados emocionais e suas consequências para a ação humana. Tendo em vista o menor grau de racionalidade de seu curso e devido a sua irracionalidade de fins, as ações emocionais (como aquelas motivadas por dignidade, orgulho, inveja ou ciúmes) interferem somente de maneira indireta no curso externo da ação - ainda que se relacionem significativamente com a ação de terceiros.

Na parte 'antiga' de Kategorien, Weber trata indiretamente os afetos e emoções como comportamentos interiores, nos quais é possível depositar expectativas. Ele não reconhece aqui, portanto, a possibilidade de orientar um comportamento emocional interno pela ação alheia, mas somente que uma ação esteja referida ao afeto de outrem. Assim, enquanto na parte 'nova' de Kategorien Weber reconhece a existência de ações emocionais, na parte 'antiga' ele as retrata como um comportamento interno. 
No que tange às diferenças entre ações orientadas por afetos e emoções e ações orientadas por valores, analisando o texto de 1921 pode-se afirmar que ela reside na consciência da orientação da ação. Enquanto a ação afetiva orienta-se por estados internos, a ação de valores é conscientemente orientada por um princípio ético, estético ou religioso, tomado como máxima. A fim de demarcar com precisão e clareza tais diferenças, Gert Albert (2002) inseriu no debate especializado sobre a teoria da ação de Weber o modelo causal da Teoria da Ação de Vilfredo Pareto, ilustrado na Figura 1.

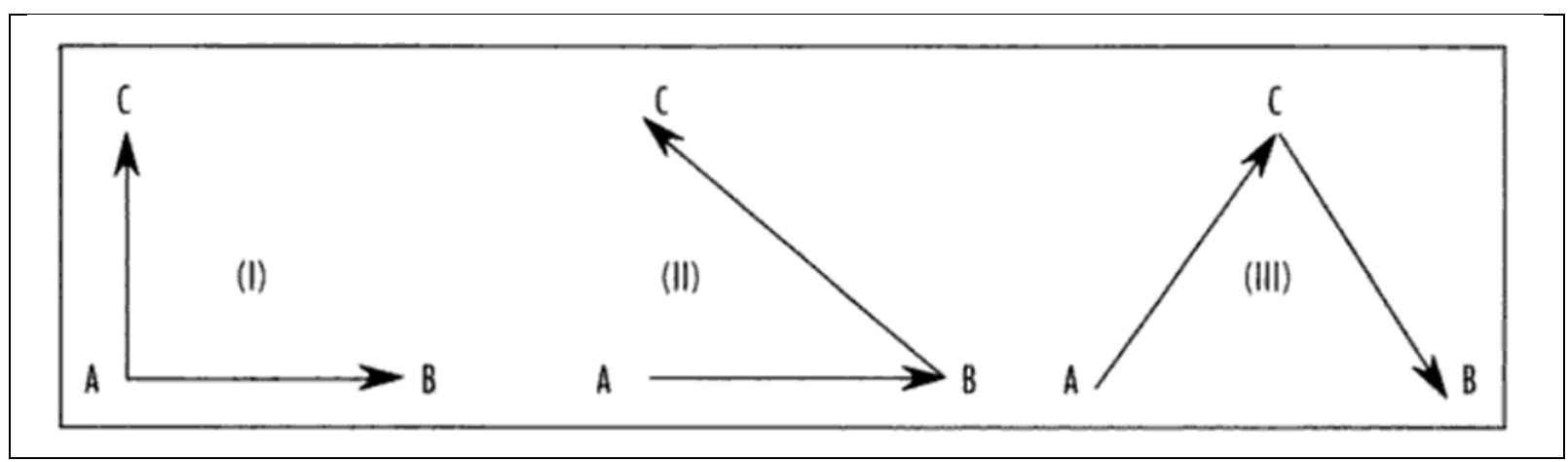

Figura 1 - Modelo causal da Teoria da Ação de Pareto Fonte: Schluchter (2005).

Na Figura 1, os vetores (I) retratam o processo de formação de um comportamento. Nesse contexto, o estado psíquico A gera, concomitantemente, o sentido $\mathrm{C}$ e o comportamento $\mathrm{B}$, sendo que não há conexão direta entre $\mathrm{B}$ e $\mathrm{C}$. Já os vetores (II) ilustram o estado mental A que provoca o comportamento B, o qual, por sua vez, funda a crença $C$. Essa a situação, em que pessoas acreditam em $C$ porque fazem B, pode ser aproximada da ação afetiva de Weber, pois o sentido 'C' não é tomado como a finalidade da ação, mas como o resultado do comportamento B. Os vetores (III) da Figura 2, por outro lado, sinalizam a existência de um estado mental A que provoca a convicção $C$, que, por sua vez, produz o comportamento B. Essa proposição possui afinidades com o modelo da ação racional com referência a valores, pois o comportamento B só se desenrola com vistas à crença em C tomada como uma máxima normativa.

Sob essa lógica causal, age de maneira puramente racional com referência a valores quem orienta-se pela convicção consciente em uma 'causa' de qualquer 
natureza - como, por exemplo, a convicção em um valor ético (como princípios, deveres, convicções, ideologias ou dignidade), estético (como padrões estéticos de grupos) ou religioso (mandamentos religiosos). Essas convicções servem como 'mandamentos' ou 'exigências', nos quais o agente crê e os toma como normas pra a realização de sua ação (WEBER, 1921). Nesse aspecto, de acordo com Schluchter (200o), a ação racional com referência a valores tem afinidades com o modelo kantiano do imperativo categórico ${ }^{10}$.

Ao analisar minuciosamente o texto Kategorien, é possível perceber que a sua conceituação da ação com referência a valores é semelhante àquela desenvolvida em Grundbegriffe. Em ambas as partes do texto de 1913 Weber retrata os valores como um comportamento interno significado subjetivamente por sua relação consciente a valores pessoais considerados um 'dever', uma 'máxima' e uma 'obrigação'. Tal ação orientada por valores pode, inclusive, ser um tipo objetivamente correto - à semelhança do que é a ação de fins.

Como revela Schluchter (2011), oportunamente, Weber se interessou desde cedo, especialmente na Ética protestante, pela não redução dos valores aos fins da ação. Nesse estudo ele demonstrou que a gênese do 'espírito' do capitalismo moderno está assentada na racionalidade valorativa e não em uma racionalidade finalística. $\mathrm{O}$ puritano tem sua ação motivada pelo valor moral religioso. O capitalista por sua vez, é o produto final do processo de secularização, e, por isso, configura um modelo autônomo frente ao puritano. Isso revela que a ação com referência a valores, por ser racional, não deve ser reduzida a uma variante do cálculo de utilidade. Ela é, em tese, em modelo de ação intimamente distinto da ação finalística.

A ação racional com referência a valores, diferentemente da ação racional com referência a fins, não estipula 'fins' ou 'resultados' a serem alcançados, nem as

\footnotetext{
${ }^{10}$ Os imperativos categóricos de Kant (2001) são máximas aceitáveis como leis universais que não podem ser desobedecidas. É dever de toda pessoa agir segundo princípios que considera benéficos, caso fossem seguidos por todos os seres humanos. É uma necessidade moral que os indivíduos coloquem à prova os princípios consigo mesmos, antes de impô-los aos outros. Por meio disso, Kant propõe construir uma ética racional e prática por meio da qual se age de forma moralmente correta. Weber (1921) não forma um tipo de ação correta, como propõe Kant, mas dialoga com a ação movida por princípios como 'mandamentos'.
} 
'consequências' de sua ação"1. Conforme defende Schluchter (2014), grande parte das ações relacionadas a valores, ainda que racionais, não consideram os meios e os fins da ação como uma questão central ${ }^{12}$. Antes, elas são determinadas pela crença consciente em um valor absoluto e inerente ao comportamento. Assim, se na ação de fins os propósitos são racionais, na ação de valores as crenças o são.

Em uma comparação estrita entre a ação racional com referência a fins e a ação racional com referência a valores, esta última sempre terá caráter irracional. Isso porque, quanto mais um valor é considerado absoluto em uma dada ação, menos seus fins e suas consequências são ponderados. É importante destacar, de todo modo, que ambas as ações são tipos ideais construídos. Determinar esses limites na realidade empírica é um exercício complexo. Até mesmo porque são raros os casos empíricos em que uma ação se orienta exclusivamente por fins ou por valores ${ }^{13}$.

Por isso, pode haver 'desvios' na consideração racional típica-ideal de meios, fins e consequências da ação. Weber (1921) exemplifica tais desvios por meio de dois casos, descritos a seguir. Há situações em que os agentes estipulam fins para as suas ações que concorrem com as suas vontades e necessidades subjetivas. Eles ponderam conscientemente as suas ações em uma escala de 'urgência', em consonância com o princípio da utilidade marginal ${ }^{14}$, e as cumprem de acordo com esse grau maior ou menor de necessidade. Há casos em que, por outro lado, o agente pondera os fins e as

\footnotetext{
${ }^{11}$ Sob uma leitura distinta de Schluchter (2014), Jens Greve defende que tanto na ação racional de fins quanto na de valores, em contraposição à ação tradicional e afetiva, há uma estrutura de fins e meios. Mesmo que essa informação não esteja precisada no texto, é possível deduzir que em ambos os casos os atores buscam por objetivos específicos, ainda que sob circunstâncias distintas. Se na ação de fins o ator escolhe pelo maior benefício e êxito de sua ação, na ação de valores ele age com a finalidade de cumprir o dever ético. Em consonância, Esser (2001 apud GREVE, 2003) adota a perspectiva de que a ação de valores funciona como a ação de fins. Afinal, sob sua perspectiva, nela o agente considera as consequências possíveis de sua ação e, a partir disso, chega à conclusão de que não considerará mais tais consequências, haja vista a preservação da ordem social em geral.

${ }^{12}$ Há ações racional-valorativas em que as consequências são importantes, fundamentais e justificáveis. É o caso das máximas morais (SCHLUCHTER, 2014).

${ }^{13}$ Há abordagens recentes que reconstrõem a relação entre a ação de fins e a ação de valor weberianas. O estudo de Jens Greve (2003), a saber, faz um balanço crítico de três abordagens contemporâneas que integram a ação racional e a ação de valor: a de Raymond Boudon, de Siegwart Lindenberg e de Hartmut Esser. A questão de pano de fundo desse estudo, que vem a largos anos sendo debatida na literatura especializada, é a possibilidade de integrar na mesma teoria uma ação racional de fins e valores.

${ }^{14}$ A lei da utilidade marginal, que advém da economia, propõe a existência de uma relação inversamente proporcional entre utilidade e quantidade/oferta de uma determinada coisa. Um exemplo é a água versus o diamante. A água possui grande utilidade total, mas baixa utilidade marginal já que é abundante. O diamante, por sua vez, como é escasso, possui alta utilidade marginal.
} 
consequências de forma incompatível. Isso pode ser explicado pela orientação racional da ação concomitantemente por fins e por valores. Nesse caso, a ação só é racional com referência a fins no que se refere aos meios.

A ação racional com referência a fins em seu tipo ideal 'puro' é determinada, em Grundbegriffe, pela utilização da expectativa do comportamento de outras pessoas e/ou da expectativa de comportamento de objetos como meios para alcançar fins estipulados. Todas as 'etapas' dessa ação são ponderadas: meios, fins e consequências. Assim, o agente considera fins que serão perseguidos racionalmente, atenta para os meios necessários para alcançar esses fins e pondera os meios em relação às possíveis consequências secundárias.

É importante ressaltar que, entretanto, há uma delicada diferença na apresentação da ação racional com referência a fins na parte 'nova' de Kategorien (capítulos 1 a 3) e na parte 'antiga' (capítulos 4 a 7). Algo que, de acordo com Schluchter (2014), comprova a diferença temporal na redação de ambas as partes do ensaio. Nas seções 1 a 3, a ação racional com relação a fins é apresentada como uma ação instrumental, calculabilizada e objetivamente correta. Já das seções 4 a 7 , essa ação é enquadrada no contexto da ação em comunidade, e, portanto, é apresentada como uma ação orientada por expectativas subjetivamente geradas. Em vista disso, em consonância com Schluchter (2011), é possível afirmar que Weber prioriza o esquema de interpretação racional com relação a fins, especialmente na primeira parte das Kategorien, quando ele enfatiza a racionalidade objetivamente correta, cuja função é elaborar casos limites de ações racionais finais.

Não obstante, há um tipo de ação de Grundbegriffe que não está contemplada em Kategorien: a ação tradicional. Em 1921, Weber realmente parece reconhecer as experiências da vida diária, ao fundamentar a sua tese da ação tradicional. Na sucessão diária de atos, em meio a tantos afazeres, há a tendência de ações automatizadas. Não encontramos nenhum sentido evidente em ações desse tipo, pois elas estão rotinizadas - ainda que, conforme bem destaca Schütz (2018), essas ações tenham significação subjetiva para o próprio agente.

Por isso, entre a ação afetiva e a ação tradicional, é possível destacar mais semelhanças do que dissonâncias. Tanto o comportamento estritamente tradicional 
quanto o comportamento estritamente afetivo estão no limite da ação conscientemente orientada pelo sentido. Frequentemente, a ação tradicional, como é determinada pelo costume arraigado, é uma reação surda/obscura a estímulos habituais. A ação afetiva, por outro lado, pode ser uma reação desenfreada, descomedida e desregrada a um estímulo afetivo não-cotidiano.

Ainda assim, é importante ressaltar, que é possível racionalizar as ações tradicionais e as ações afetivas via fins ou via valores, especialmente quando essas ações são mantidas conscientemente. No caso da ação afetiva, por meio de uma descarga consciente do estado emocional (sublimação). Já na ação tradicional, por meio de uma vinculação consciente ao hábito. Cabe ressaltar que a racionalização de ações não racionais pode acontecer para o agente (o ator da ação propriamente dito) e para o observador.

\section{Considerações finais}

É possível afirmar que a definição de ação foi modficada em Grundbegriffe, se comparada à conceituação de Kategorien? Schluchter (2014) defende que o conteúdo do conceito não foi transformado. A formulação foi apenas sofisticada e deslindada. Em ambos os ensaios a ação é entendida como um comportamento humano de fazer interno (motivação) e externo (seu desenrolar voltados a objetos no mundo) dotado de sentido subjetivamente visado.

Se atentarmos para as mudanças no interior de sua formulação, perceberemos que Weber qualificou de formas sensivelmente distintas os tipos de ação em 1913 e em 1921. Se na parte 'antiga' de Kategorien Weber considerava a ação afetiva como um comportamento interno motivado por afetos e emoções, e sem referência estrita ao comportamento alheio, na parte 'nova' ele admite a existência de ações emocionais ainda que elas interfiram somente de maneira indireta no curso da ação. Mas é somente em Grundbegriffe que o autor retrata a ação afetiva como uma ação social referida a afetos pessoais e, ao mesmo tempo, orientada a comportamentos alheios.

Desde o estudo sobre Stammler, ainda quando Weber se ocupava com a economia e o direito, ele introduziu a diferenciação entre ações orientadas por 
máximas valorativas e ações orientadas por máximas finais. Em Kategorien essa discussão ficou descentralizada, pois Weber optou por evidenciar o dualismo de Tönnies (com a ação em comunidade e a ação societária) e as ações consensuais. Mas em Grundbegriffe, ela é retomada e utilizada como uma inovação decisiva em relação ao método (SCHLUCHTER, 2011), especialmente pela racionalização dos valores.

Conforme destaca Turner (1983), ao descentralizar o papel das expectativas e da possibilidade objetiva, que vigoravam no texto de 1913, Weber pôde evidenciar outras formas de ação racional. Desse modo, ele conseguiu equivaler hierárquica e metodologicamente os dois tipos de ação racional em Grundbegriffe: a ação de fins e de valores. A partir dessa perspectiva, Weber (1921) demonstrou que há ações ajustadas por valores. Essas ações podem ser intimamente racionais quanto mais consciente e claro for o valor para o próprio agente.

Weber (1921) também inova ao incluir a ação com relação a fins como uma ação que compõe a sua tipologia quádrupla. Em 1913, especificamente na parte 'nova', a ação de fins aparecia como um caso-limite de análise de ação instrumental, um tipo objetivamente correto passível de comparação. Já em 1921, além de ser a ação em estado ideal de análise, ela é também um tipo de ação de seu arquétipo. Nisso a categorização de Grundbegriffe se aproxima daquela outrora desenvolvida na parte 'antiga' de Kategorien. Afinal, em ambas Weber aceita a existência da ação orientada por fins e referida ao comportamento de outros agentes. Isso é, uma ação que é racional em sua dimensão subjetiva e objetiva.

Em vista dessas considerações, é possível afirmar que Weber possui três tipologias da ação: a da parte 'antiga' de Kategorien, a da parte 'nova' de Kategorien e a de Grundbegriffe. Sendo que, nesse cenário, a tipologia que mais se aproxima de sua formulação final de 1921 é aquela que chamamos de parte 'nova' de Kategorien, porque é na parte 'nova' que Weber acena para a possibilidade de que comportamentos motivados por emoções sejam ações, e para o fato de que as ações de fins são tiposideais que servem como parâmetro comparativo.

Há, ainda, uma exclusividade efetiva de Grundbegriffe: a ação tradicional. Foi somente em 1921 que Weber reconheceu a existência de ações sociais quase automatizadas, rotinizadas e reativas. Uma ação que, se comparada às ações racionais 
(como a referida a valores e a referida a fins), pode ser intitulada defizitäre Modi [modos deficitários] (NORKUS, 2001) ou residual categories [categorias residuais] (PARSONS, 1940).

Em tese, há duas diferenças fundamentais entre as tipologias desses textos: 1) em Grundbegriffe Weber admite a análise intelectual, tanto de ações racionais e quanto de ações afetivas e tradicionais; e 2) em 1921 ele retoma seu debate com Stammler sobre as ações orientadas por máximas valorativas e por máximas finais e inova, com isso, sua tipologia. Ele equivale metodologicamente os dois tipos de ação racional: a ação de fins e de valores. É importante ressaltar que em ambos os ensaios Weber prioriza a análise da ação racional, pois ela possui compreensibilidade evidente. Somente para fins de conveniência metodológica, a Sociologia Compreensiva é 'racionalista'. Com base nisso, defendemos que a possível interpretação de uma normatividade racionalista, existente em Kategorien, é em Grundbegriffe erradicada. Com o abandono da racionalidade objetivamente correta e a consequente adoção da racionalidade de fins e de valores, seu "racionalismo heurístico" perdeu a centralidade.

\section{Referências}

ALBERT, Gert. Paretos hermeneutischer Positivismus. Eine analyse seiner Handlungstheorie. Kölner Zeitschrift für Soziologie und Sozialpsychologie, n. 54, 2002.

GREVE, Jens. Handlungserklärung und die zwei Rationalitäten? Neuere Ansätze zur Integration von Wert- und Zweckrationalität in ein Handlungsmodell. Kölner Zeitschrift für Soziologie und Sozialpsychologie, v. 55, n. 4, 2003.

. Wirtschaft und Gesellschaft. Soziologie (1919/1920). In: MÜLLER, Hans-Peter; SIGMUND, Steffen. Max Weber Handbuch: Leben - Werk - Wirkung. Stuttgart: J. B. Metzler, 2014.

KANT, Immanuel. Crítica da razão pura. Lisboa: Serviço de Educação, 2001.

LICHTBLAU, Klaus. Max Weber's 'Sociology' as seen against the history of his work. Max Weber studies, Londres, v. 15, n. 2, 2015.

NORKUS, Zenonas. Max Weber und Rational Choice. Marburg: Metropolis-Verl., 2001. 
PARSONS, Talcott. An analytical approach to the theory of social stratification. [1940]. In: PARSONS, Talcott. Essays in Sociological Theory. New York: Revised Edition, 1954 .

REHBERG, Karl-Sirgbert. Handeln und Handlung. In: MÜLLER, Hans-Peter; SIGMUND, Steffen. Max Weber Handbuch: Leben - Werk - Wirkung. Stuttgart: J. B. Metzler, 2014.

SCHNEIDER, Wolfgang Ludwig. Sinn. In: MÜLLER, Hans-Peter; SIGMUND, Steffen. Max Weber Handbuch: Leben - Werk - Wirkung. Stuttgart: J. B. Metzler, 2014.

SCHÜTZ, Alfred. A construção significativa do mundo social. Petrópolis: Editora Vozes, 2018.

SCHLUCHTER, Wolfgang. Individualismus, Verantwortungsethik und Vielfalt. Weilerswist: Velbrück Wissenschaft, 2000.

. Handlung, Ordnung und Kultur. Heidelberg: Mohr Siebeck, 2005.

Acción, orden y cultura: estúdios para um programa de investigación em conexión com Max Weber. Buenos Aires: Prometeu, 2011.

- Os conceitos sociológicos fundamentais: a fundamentação da sociologia compreensiva de Max Weber. In: SCHLUCHTER, Wolfgang. O desencantamento do mundo: seis estudos sobre Max Weber. Rio de Janeiro: Editora UFRJ, 2014.

TURNER, Stephen. Weber on action. American Sociological Review, v. 48, 1983.

WEBER, Max. Stammler's "Überwindung” der materialistischen Geschichtsauffassung. In: WEBER, Max. (Org. Johannes Winckelmann). Max Weber: Gesammelte Aufsätze zur Wissenschaftslehre. Tübingen: Mohr Siebeck, 1985 [1907].

$[G d S] \ldots$ _ (org.). Grundriss der Sozialökonomik. Tübingen: Mohr Siebeck, 1914, vol. I.

$[W u G]$ Wirtschaft und Gesellschaft: Grundriss der verstehenden Soziologie. Tübingen: Mohr Siebeck, 1985 [1921].

Kritische Studien auf dem Gebiet der kulturwissenschaftlichen Logik. In: WEBER, Max. (Org. Johannes Winckelmann). Max Weber: Gesammelte Aufsätze zur Wissenschaftslehre. Tübingen, 1985 [1906].

[MWG I/23] _. Wirtschaft und Gesellschaft: Soziologie (1919-1920). Knut Borchardt, Edith Hanke e Wolfgang Schluchter (Eds.) Tübingen: Mohr Siebeck, 2013. 
[MWG I/12] _ _. Verstehende Soziologie und Werturteilsfreiheit: schriften und reden (1908-1917). Johannes Weiss e Sabine Frommer (Eds.) . Tübingen: Mohr Siebeck, 2018.

[EeS $]$ Economia e sociedade: fundamentos da sociologia compreensiva. Brasília: Editora Universidade de Brasília, 2015. 